\title{
The vibration characters analysis of tube compressor
}

\author{
Xiaolong Zhang ${ }^{1,2, a}$, Keke Gao ${ }^{1, b}$, Zhen Shen ${ }^{2, \mathrm{c}}$ and Yonghui Xie ${ }^{1, \mathrm{~d}^{*}}$ \\ ${ }^{1}$ Xi'an Jiaotong University, Xi'an, Shaanxi 710049, China \\ ${ }^{2}$ Xi'an Shaangu Power Co., Ltd., Xi'an, Shaanxi 710611, China \\ âwhoxlzhang@163.com, ㄷ․K.K1990@stu.xjtu.edu.cn, 'ShaanGuCAE@163.com, \\ dyhxie@mail.xjtu.edu.cn
}

Keywords: rotor-bearing system; finite element; critical speed.

\begin{abstract}
The finite element model of rotor-bearing system in large tube compressor based on the beam element which can be used to analyze gyroscope effect is established and the bearing parameters changed with rotation speed are considered. The first and second critical speed of rotor-bearing system can be found with the ANSYS 12.0 commercial software, and the Campbell diagram which represents the characteristic frequency varying with rotation speed is shown in the paper. The critical speed and whirl orbits of the rotor-bearing system have been demonstrated; meanwhile, a computational method for the investigation on the critical speed of overall unit is presented.
\end{abstract}

\section{Introduction}

The reliable operation of overall unit depends on the rotor-bearing system largely [1].The investigation on dynamics characters of large rotor-bearing system has a guiding significance to the safe unit operation. The critical speed and whirl orbits of rotor-bearing system in large tube compressor have been obtained varying with bearing parameters. Meanwhile the gyroscope effect is under consideration during the simulation process. The conclusions provide a positive reference for the reliable and optimum design of rotor-bearing system.

\section{The rotor-bearing system dynamics model}

The compressor rotor which is supported with two tilting-pad bearings contains six stage impellers. The simplifications have been conducted for analysis as follows [2]:

(1) The Timoshenko beam element is adopted for spindle of rotor-bearing system. The BEAM 188 of three dimensional two node linear beam is applied in the paper. Each nodes contains six freedom which means $\mathrm{x}, \mathrm{y}, \mathrm{z}$ displacement and rotation.

(2) The six stage impellers and coupling are applied to rotor-bearing system in the form of attached mass and rotational inertial. The MASS 21 element is applied to simulate attached mass of impeller and coupling; meanwhile, the rotational inertial of impeller and coupling is applied through constant parameters definition.

(3) The supported bearing is regarded as spring-damping element. COMBI 214 which is shown in Fig. 1 is applied in the paper. Four bearing stiffness coefficients $\left(\mathrm{K}_{11}, \mathrm{~K}_{12}, \mathrm{~K}_{21}, \mathrm{~K}_{22}\right)$ and damping coefficients $\left(\mathrm{C}_{11}, \mathrm{C}_{12}, \mathrm{C}_{21}, \mathrm{C}_{22}\right)$ are allowed for bearing setting. 

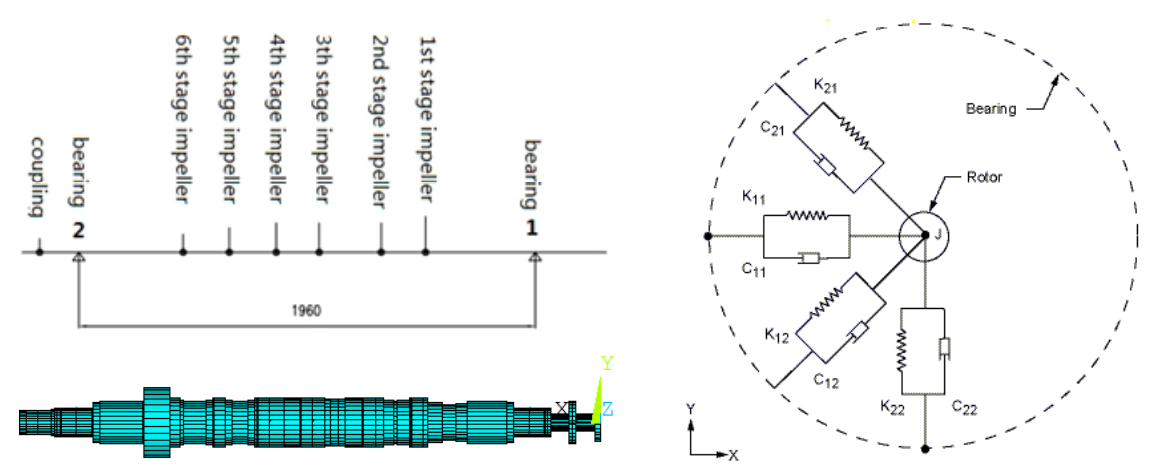

Fig.1 Compressor rotor-bearing system schematic diagram

\section{Solution and Analysis of Critical Speed}

Motion Equation of Rotor-bearing System. In general, the motion equation of rotor-bearing system with $\mathrm{N}$ nodes (N-1 rotor segments) can be described as follows:

$$
\left.\begin{array}{l}
{\left[M_{1}\right]\left\{U_{1}^{\prime \prime}\right\}+\Omega\left[J_{1}\right]\left\{U_{2}^{\prime}\right\}+\left[K_{1}\right]\left\{U_{1}\right\}=\left\{Q_{1}\right\}} \\
{\left[M_{1}\right]\left\{U_{2}^{\prime \prime}\right\}-\Omega\left[J_{1}\right]\left\{U_{1}^{\prime}\right\}+\left[K_{1}\right]\left\{U_{2}\right\}=\left\{Q_{2}\right\}}
\end{array}\right\}
$$

where $\left[M_{1}\right], \Omega\left[J_{1}\right],\left[K_{1}\right],\left\{Q_{1}\right\}$ and $\left\{Q_{2}\right\}$ means mass matrix, rotating matrix, stiffness matrix and two generalized forces of system support, respectively.

For the rotor-bearing system with plain bearing, Eq. (1) can be transformed to Eq. (2) with the consideration of oil film force on shaft neck.

$$
\left[\begin{array}{cc}
M_{1} & 0 \\
0 & M_{1}
\end{array}\right]\left\{\begin{array}{l}
U_{1}^{\prime \prime} \\
U_{2}^{\prime \prime}
\end{array}\right\}+\left[\begin{array}{cc}
c_{11} & c_{12}+\Omega\left[J_{1}\right] \\
c_{21}-\Omega\left[J_{1}\right] & c_{22}
\end{array}\right]\left\{\begin{array}{l}
U_{1}^{\prime} \\
U_{2}^{\prime}
\end{array}\right\}+\left[\begin{array}{cc}
k_{11}+K_{1} & k_{12} \\
k_{21} & k_{22}+K_{1}
\end{array}\right]\left\{\begin{array}{l}
U_{1} \\
U_{2}
\end{array}\right\}=\left\{\begin{array}{l}
Q_{1} \\
Q_{2}
\end{array}\right\}
$$

The Eq. (3) can be obtained through Eq. (2) for the simplification.

$$
[M]\left\{U^{\prime \prime}\right\}+[C]\left\{U^{\prime}\right\}+[K]\{U\}=[Q]
$$

The Eq. (4) can be derived from Eq. (3) for anisotropic bearing.

$$
[M]\left\{U^{\prime \prime}\right\}+[C]\left\{U^{\prime}\right\}+[K]\{U\}=0
$$

$\omega(\Omega)$ which means characteristic value varying with rotor angular speed $(\Omega)$ can be obtained through the band matrix above. The critical speed of system can be solved when $\omega(\Omega)$ is equal to $\Omega$. Rotor-bearing Parameters. The mass of rotor-bearing system is $787.8 \mathrm{~kg}$ and the distance between two bearings is $1960 \mathrm{~mm}$. The density, Young modulus and Poisson's ratio are $7850 \mathrm{~kg} / \mathrm{m}^{3}$, $2.059 \mathrm{E} 11 \mathrm{~N} / \mathrm{m}^{2}$ and 0.2998 . The parameters of impeller and coupling are shown in Table 1.

Table 1 Parameters of impeller and coupling

\begin{tabular}{c|c|c|c|c|c|c|c}
\hline Name & Impeller 1 & Impeller 2 & Impeller 3 & Impeller 4 & Impeller 5 & Impeller 6 & coupling \\
\hline Mass $(\mathrm{kg})$ & 43.7 & 42 & 45 & 47 & 31.72 & 27.87 & 40.9 \\
\hline Rotational inertia $\left(\mathrm{kg} \cdot \mathrm{m}^{2}\right)$ & 1.205 & 1.062 & 1.138 & 1.188 & 0.741 & 0.608 & 0.370 \\
\hline
\end{tabular}

The constant values of oil film stiffness and damping parameters are generally applied in the investigations of critical speed with large rotor-bearing system. Moreover, the cross stiffness and damping effect are easily neglected in the analysis [3]-[6]. However, the stiffness and damping coefficient varies with rotational speed for most rotor-bearing systems [7]. In fact, the cross coupling of oil film stiffness and damping plays a major role in the instability of rotor system [8]. Therefore, the oil film stiffness and damping variations, as well as the influence of cross stiffness 
and damping are considered when the dynamics characteristics are analyzed in the paper.

Table 2 Stiffness parameters of bearing 1

Table 3 Damping parameters of bearing 1

\begin{tabular}{l|l|l|l|l}
\hline $\begin{array}{l}\text { Speed } \\
(\mathrm{rpm})\end{array}$ & $\mathrm{K}_{11}(\mathrm{~N} / \mathrm{m})$ & $\mathrm{K}_{22}(\mathrm{~N} / \mathrm{m})$ & $\mathrm{K}_{12}(\mathrm{~N} / \mathrm{m})$ & $\mathrm{K}_{21}(\mathrm{~N} / \mathrm{m})$ \\
\hline 2300 & $8.50 \mathrm{E}+07$ & $8.50 \mathrm{E}+07$ & $3.72 \mathrm{E}+04$ & $3.72 \mathrm{E}+04$ \\
\hline 4600 & $1.06 \mathrm{E}+08$ & $1.06 \mathrm{E}+08$ & $1.18 \mathrm{E}+04$ & $1.18 \mathrm{E}+04$ \\
\hline$\ldots$ & $\ldots$ & $\ldots$ & $\ldots$ & $\ldots$ \\
\hline 25300 & $4.49 \mathrm{E}+08$ & $4.49 \mathrm{E}+08$ & $-1.06 \mathrm{E}+04$ & $-1.06 \mathrm{E}+04$ \\
\hline
\end{tabular}

Table 4 Stiffness parameters of bearing 2

\begin{tabular}{c|c|c|c|c}
\hline $\begin{array}{c}\text { Speed } \\
(\mathrm{rpm})\end{array}$ & $\mathrm{K}_{11}(\mathrm{~N} / \mathrm{m})$ & $\mathrm{K}_{22}(\mathrm{~N} / \mathrm{m})$ & $\mathrm{K}_{12}(\mathrm{~N} / \mathrm{m})$ & $\mathrm{K}_{21}(\mathrm{~N} / \mathrm{m})$ \\
\hline 2300 & $9.97 \mathrm{E}+07$ & $9.97 \mathrm{E}+07$ & $3.12 \mathrm{E}+04$ & $3.12 \mathrm{E}+04$ \\
\hline 4600 & $1.15 \mathrm{E}+08$ & $1.15 \mathrm{E}+08$ & $2.33 \mathrm{E}+04$ & $2.33 \mathrm{E}+04$ \\
\hline$\ldots$ & $\ldots$ & $\ldots$ & $\ldots$ & $\ldots$ \\
\hline 25300 & $4.51 \mathrm{E}+08$ & $4.51 \mathrm{E}+08$ & $-1.14 \mathrm{E}+04$ & $-1.14 \mathrm{E}+04$ \\
\hline
\end{tabular}

\begin{tabular}{c|c|c|c|c}
\hline $\begin{array}{c}\text { Speed } \\
(\mathrm{rpm})\end{array}$ & $\mathrm{C}_{11}(\mathrm{~N}-\mathrm{s} / \mathrm{m}$ & $\mathrm{C}_{22}(\mathrm{~N}-\mathrm{s} / \mathrm{m}$ & $\mathrm{C}_{12}(\mathrm{~N}-\mathrm{s} / \mathrm{m}$ & $\mathrm{C}_{21}(\mathrm{~N}-\mathrm{s} / \mathrm{m})$ \\
\hline 2300 & $2.75 \mathrm{E}+05$ & $2.75 \mathrm{E}+05$ & $7.79 \mathrm{E}+01$ & $7.79 \mathrm{E}+01$ \\
\hline 4600 & $2.01 \mathrm{E}+05$ & $2.01 \mathrm{E}+05$ & $-4.43 \mathrm{E}+$ & $-4.43 \mathrm{E}+$ \\
\hline$\ldots$ & $\ldots$ & $\ldots$ & $\ldots$ & $\ldots$ \\
\hline 25300 & $1.70 \mathrm{E}+05$ & $1.70 \mathrm{E}+05$ & $0.00 \mathrm{E}+$ & $0.00 \mathrm{E}+$ \\
\hline
\end{tabular}

Table 5 Damping parameters of bearing 2

\begin{tabular}{c|c|c|c|c}
\hline $\begin{array}{c}\text { Speed } \\
(\mathrm{rpm})\end{array}$ & $\mathrm{C}_{11}(\mathrm{~N}-\mathrm{s} / \mathrm{m})$ & $\mathrm{C}_{22}(\mathrm{~N}-\mathrm{s} / \mathrm{m})$ & $\mathrm{C}_{12}(\mathrm{~N}-\mathrm{s} / \mathrm{m})$ & $\mathrm{C}_{21}(\mathrm{~N}-\mathrm{s} / \mathrm{m})$ \\
\hline 2300 & $3.06 \mathrm{E}+05$ & $3.06 \mathrm{E}+05$ & $6.48 \mathrm{E}+01$ & $6.48 \mathrm{E}+01$ \\
\hline 4600 & $2.12 \mathrm{E}+05$ & $2.12 \mathrm{E}+05$ & $6.90 \mathrm{E}+00$ & $6.90 \mathrm{E}+00$ \\
\hline$\ldots$ & $\ldots$ & $\ldots$ & $\ldots$ & $\ldots$ \\
\hline 25300 & $1.70 \mathrm{E}+05$ & $1.70 \mathrm{E}+05$ & $0.00 \mathrm{E}+00$ & $0.00 \mathrm{E}+00$ \\
\hline
\end{tabular}

Critical Speed Solution of Rotor-bearing System. The rotor rotates around the center line of bearing when rotating around itself due to the rotational moment, which produces forward and backward precession [7]. However, the critical speed of rotor-bearing system with forward precession is concerned during the normal operation [9].

Both the rotational moment and the bearing parameters (stiffness and damping parameters) varying with rotation speed are considered. Moreover, QR-Damped solver in which the effect of spring damping parameters are considered is adopted. The forward and backward whirl frequencies are demonstrated in a wide speed range from 2300rpm to 25300rpm with even speed as Table 6 .

Table 6 Forward and backward whirl frequencies of rotor

\begin{tabular}{lllllll}
\hline \multirow{2}{*}{ Speed(rpm) } & \multicolumn{6}{c}{ Whirl(Hz) } \\
\cline { 2 - 7 } & $1^{\text {st }}$ backward & $1^{\text {st }}$ forward & $2^{\text {nd }}$ backward & $2^{\text {nd }}$ forward & $3^{\text {th }}$ backward & $3^{\text {th }}$ forward \\
\hline 2300 & 64.326 & 64.652 & 278.32 & 282.31 & 478.83 & 487.81 \\
\hline 4600 & 64.16 & 64.813 & 276.33 & 284.31 & 474.33 & 492.29 \\
\hline$\ldots$ & $\ldots$ & $\ldots$ & $\ldots$ & $\ldots$ & $\ldots$ & $\ldots$ \\
\hline 25300 & 62.62 & 66.201 & 258.43 & 302.34 & 433.78 & 532.46 \\
\hline
\end{tabular}

The critical speed of rotor-bearing system can be obtained through Campbell diagram as shown in Fig.2. The first and second critical speeds are $65 \mathrm{~Hz}$ and $294 \mathrm{~Hz}$; the corresponding whirl orbits are shown in Fig.3. The first critical speed of test whose value is approximately $64 \mathrm{~Hz}$ (3850-3900 r/min) is in good agreement with computation result.

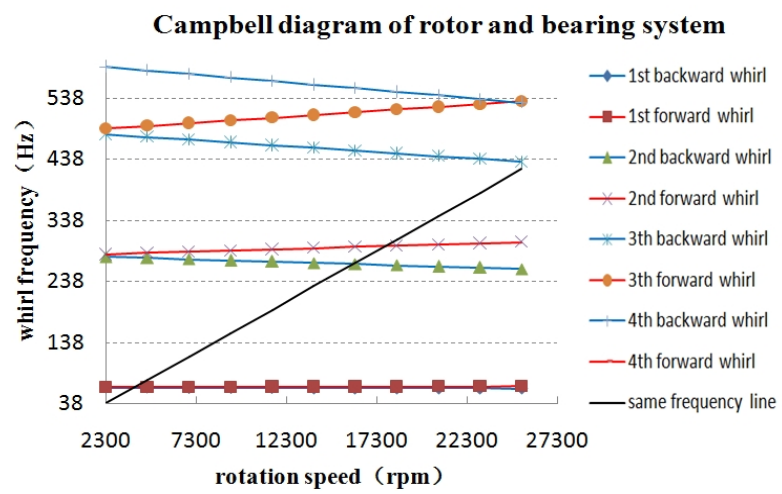

Fig.2 Campbell diagram of rotor-bearing system 

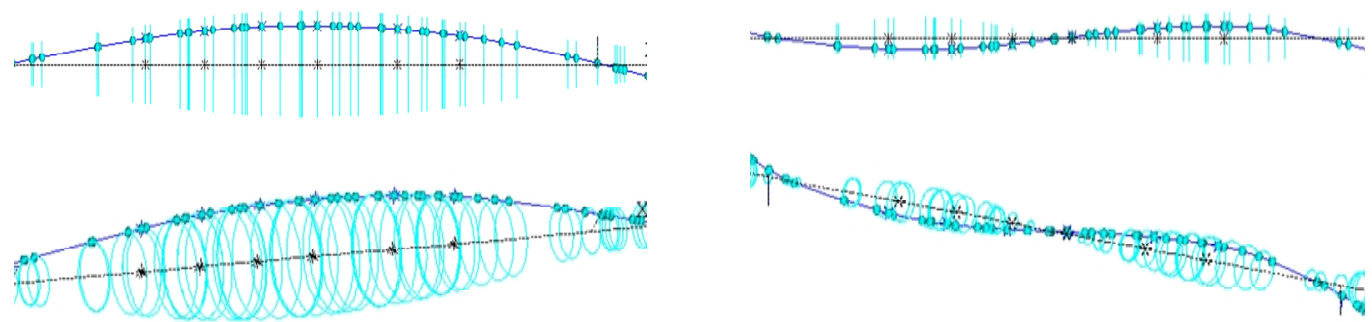

Fig.3 First order (left) and second order (right) whirl orbit of rotor-bearing system of centrifugal compressor

\section{Summary}

The dynamics analysis of rotor-bearing system of large tube centrifugal compressor is conducted based on Timoshenko beam model through ANSYS 12.0. The variations of bearing stiffness and damping parameters with rotation speed, as well as gyroscopic effect are considered in the investigation of critical speed. It is shown that the impeller rotation moment can shift the critical speed of rotor system when forward whirl happens. On the contrary, the critical speed of rotor system decreases when backward whirl happens. Meanwhile, it is shown that the Timoshenko beam model possesses high accuracy for the analysis of critical speed of rotor-bearing system. The paper provides an effective computation method for the mechanical investigation of critical speed of an overall rotor-bearing system.

\section{Reference}

[1] Sun H.Y., Zhang X.L., Rotor's critical rotation speed and modality analysis based on ANSYS, Machine Building \& Automation. 4(2008) 016

[2] Zhang Q, Cao L., Critical speed analysis based on ANSYS, Journal of Vibration Engineering. 17.S1 (2004): 234-237.

[3] Li J.F., Xu H., Ma X., et al., Calculating critical speeds of agitating shaft by FEM, Petro-chemical Equipment. 2(2003) 009.

[4] Yang F.C., Xu P.M., Ma Y.J., Finite element modal analysis of rotor-bearing-base system, Mechanical Engineer. 3(2009)69-71.

[5] Zhao Y.H., Critical speed calculation of rotor-bearing system of centrifugal compressor, Shenyang University of Technology, Shenyang, 2006.

[6] Gong J.Z., Zhong F.M., He X., et al., Model analysis and critical speed calculation on low-pressure compressor rotor of marine gas turbine based on ANSYS, Modern Manufacturing Engineering. 4 (2012): 020

[7] Wu H.Y., The structure and strength calculation of turbine components (in Chinese), Mechanical Industry Press, Beijing, 1982.

[8] Yu L., Liu H., Xie Y.B., Dynamics of bearing-rotor system, China Mechanical Engineering. 10(1999)1290-1295

[9] Zhang L.M., Wang K.M., Wu Z.G., Rotor critical speed analysis on ANSYS, Journal of Shenyang Institute of Aeronautical Engineering. 27(2010)34-37 